\title{
Cloud Service Selection Using Multicriteria Decision Analysis
}

\author{
Md Whaiduzzaman, ${ }^{1}$ Abdullah Gani, ${ }^{1}$ Nor Badrul Anuar, ${ }^{1}$ Muhammad Shiraz, \\ Mohammad Nazmul Haque, ${ }^{2}$ and Israat Tanzeena Haque ${ }^{3}$ \\ ${ }^{1}$ Faculty of Computer Science \& Information Technology, University of Malaya, 50603 Kuala Lumpur, Malaysia \\ ${ }^{2}$ School of Electrical Engineering and Computer Science, The University of Newcastle, Callaghan, NSW 2308, Australia \\ ${ }^{3}$ Department of Computing Science, University of Alberta, Edmonton, AB, Canada P6G 2M7
}

Correspondence should be addressed to Md Whaiduzzaman; wzaman@ieee.org

Received 11 October 2013; Accepted 19 December 2013; Published 13 February 2014

Academic Editors: A. N. Dudin and A. Kaloxylos

Copyright (C) 2014 Md Whaiduzzaman et al. This is an open access article distributed under the Creative Commons Attribution License, which permits unrestricted use, distribution, and reproduction in any medium, provided the original work is properly cited.

\begin{abstract}
Cloud computing (CC) has recently been receiving tremendous attention from the IT industry and academic researchers. CC leverages its unique services to cloud customers in a pay-as-you-go, anytime, anywhere manner. Cloud services provide dynamically scalable services through the Internet on demand. Therefore, service provisioning plays a key role in CC. The cloud customer must be able to select appropriate services according to his or her needs. Several approaches have been proposed to solve the service selection problem, including multicriteria decision analysis (MCDA). MCDA enables the user to choose from among a number of available choices. In this paper, we analyze the application of MCDA to service selection in CC. We identify and synthesize several MCDA techniques and provide a comprehensive analysis of this technology for general readers. In addition, we present a taxonomy derived from a survey of the current literature. Finally, we highlight several state-of-the-art practical aspects of MCDA implementation in cloud computing service selection. The contributions of this study are four-fold: (a) focusing on the state-ofthe-art MCDA techniques, (b) highlighting the comparative analysis and suitability of several MCDA methods, (c) presenting a taxonomy through extensive literature review, and (d) analyzing and summarizing the cloud computing service selections in different scenarios.
\end{abstract}

\section{Introduction}

Cloud computing (CC) is the distributed computing model which provides computing facilities and resources to the users in an on-demand pay-as-you-go model [1]. The aim of the cloud computing model is to increase the opportunities for cloud user by accessing leased infrastructure and software applications from anywhere anytime manner. Therefore, cloud computing offers a new kind of information and services that widen the new vision of information technology (IT) services $[2,3]$. The recent hype of the cloud computing and at the same time the rise of the smart mobile devices help us to envision mobile cloud computing (MCC). MCC is a distributed computing model comprise with cloud computing, mobile computing and seamless connectivity $[4,5]$. The objective of MCC is to enhance the computing and processing power of the mobile devices by offloading tasks to cloud data center [6-10]. In the cloud, the resources are hosted as software, database services, virtual servers (virtual machines), hardware, complete service workflows, or complex configurations of distributed computing systems and applications for provisioning $[11,12]$. These resources are provisioned as services and offered to the customer by the cloud service provider (CSP) [13].

Service provisioning is an important aspect of CC because it directly impacts the user experience of the service. New users and companies seeking cloud services are constantly emerging. The vast diversity among the available cloud services makes it difficult for the customer to decide whose services to use or even to determine a valid basis for their selection [14, 15]. Such decision problems have recently attracted considerable attention from industry and academia. Loyola and Franklin, for example, have explicitly applied multiple criteria decision analysis (MCDA) to assist with decision-making. MCDA is modeled after the way humans are thought to make decisions. Although a variety of different 
MCDA methods, techniques, and approaches have been studied, the basic ingredients of MCDA are the same: a finite or infinite set of actions, at least two criteria, and one decision maker (DM). With these elements, MCDA assists in decision making mainly by choosing, ranking, or sorting the actions. Consequently, MCDA is not only a collection of theories, methodologies, and techniques but also a specific perspective for dealing with decision-making problems [16].

Over the past few decades, decision-making theory has been successfully applied in a growing number of diverse domains and has assisted in decision making, including several well-known examples. The multicriteria decisionmaking (MCDM) approach is capable of handling multiple conflicting criteria [17]. This study provides an in-depth analysis of several MCDA/MCDM-related methods and models, as well as some insight into the state-of-the-art in decision analysis techniques $[18,19]$. Multicriteria decision making is a subfield of operations research that addresses techniques to solve multicriteria problems such as the cloud service selection problem. All MCDA methods depend on a matrix called the evaluation matrix, decision matrix, and payoff matrix or evaluation table [20].

One objective of this study is to survey the literature and to provide a critical assessment of the available MCDA techniques and their usage in service selection for cloud computing. A literature review is used to demonstrate the integration of MCDA techniques and cloud computing based on their usage and popularity. Hence, in this paper, we reviewed the current literature and identified the different types of problems. The limitations of the various methods and techniques and their pros and cons are also discussed. We highlight the fact that most MCDA techniques have often been used individually in previous studies. Finally, we provide crucial information through reviewing the available literature on MCDA techniques and its usage in service selections in cloud computing [18].

Hence, we identify our contribution of this review are four-fold: (a) focusing on the state-of-the-art MCDA techniques, (b) highlighting the comparative analysis and suitability study of several MCDA methods, (c) presenting a taxonomy through extensive literature review, and (d) analyzing and summarizing the cloud computing service selections in different practical implementation aspects.

The rest of this paper is organized as follows. Section 2 describes the background of MCDA. Section 3 discusses the fact that several MCDA applied methods can be applied in MCDM. Section 4 describes the performance of several of these methods as applied to cloud computing service selection. Section 5 provides the conclusion. The list of acronyms frequently used in this paper is shown at the end of the paper.

\section{Background of MCDA}

In 1951, Harold William Kuhn and Albert William Tucker introduced the vector maximum problem, the first explicit consideration of the basic concepts of MCDA. In 1972, a conference on "Multiple Criteria Decision Making (MCDM)" was held at Columbia University in South Carolina. Since then MCDA/MCDM has experienced rapid growth and continues to grow today [16]. A taxonomy of MCDA is presented in Figure 1.

MCDA, one of the most important branches of operations research, aims to design mathematical and computational tools for selecting the best alternative among several choices, with respect to specific criteria, either by a single decision maker or by a group. The field consists of two main categories: multiattribute decision making (MADM) and multiobjective decision making (MODM). According to a survey conducted to evaluate the use of different methods, especially for improving quality, fuzzy was the most frequently used, representing $40 \%$ of the total, followed by AHP and ANP together at approximately $20 \%$. TOPSIS was also widely used. In contrast, DEA, Goal Programming, and ELECTRE were employed only rarely [21].

(i) MCDM is a collection of methodologies for comparing, ranking, and selecting multiple alternatives, each having multiple attributes. It depends on a matrix called the evaluation matrix, decision matrix, payoff matrix, or evaluation table.

(ii) MCSP selects the best alternative from a finite set of alternatives, all of which are known a priori.

(iii) MCMP selects the best alternative from a very large or infinite set of alternatives, not all of which are known a priori.

(iv) MAUT finds a utility function reflecting the usefulness of a particular alternative.

\section{MCDA Methods}

MCDA methods can be categorized into two types: (1) multiattribute utility theory (MAUT) and (2) outranking methods. MAUT attempts to find a function reflecting the utility or usefulness of a particular alternative. Each action is assigned a marginal utility, with a real number representing the preferability of the considered action. The returned utility is the sum of these marginal utilities. Outranking methods decide whether one alternative is ranked higher than another by employing a pairwise comparison.

MCDA methods are divided into multiobjective decision making (MODM) and multiattribute decision making (MADM). The two methods differ mainly by how the alternatives are enumerated. In MODM, they are not predetermined but arise from the optimization of a set of objective functions. In MADM, they are predetermined, and a small subset is evaluated against a set of attributes. In both methods, the best alternative is chosen by comparing the rankings of each alternative/attribute combination $[16,20]$.

3.1. Analytic Hierarchy Process (AHP). In 1980, Thomas L. Saaty discovered AHP, a popular and widely used method for MCDA. AHP allows the use of qualitative as well as quantitative criteria when evaluating alternatives and the attributes are not entirely independent of each other. The AHP is based on a pairwise comparison, with the attributes structured into a hierarchal relationship, which is very useful. 




Figure 1: Taxonomy of MCDA.

The hierarchy starts from the top level towards the goal; the lower levels correspond to criteria, subcriteria, and so on. In this hierarchy tree, the process starts from leaf nodes and progresses up to the top level. Each output level represents the hierarchy corresponding to the weight or influence of different branches originating for that level. Finally, after making the comparisons, the best alternative with respect to each attribute is usually selected [22].

3.2. Analytic Network Process (ANP). ANP is an extension of AHP proposed by Thomas L. Saaty in 1996. It is a comprehensive decision-making technique designed to overcome the problem of dependence and feedback among the criteria, using unidirectional hierarchical relationships between decision levels. ANP describes interrelationships among the decision levels and attributes using unidirectional hierarchical relationships with dependence and feedback, employing ratio scale measurements based on pairwise comparisons to model the decision problem. To handle interdependence among elements, ANP derives a "supermatrix" containing composite weights [5]. ANP has been applied successfully in many real-world decision-making problems [23].

3.3. Technique for Order of Preferences by Similarity to Ideal Solution (TOPSIS). This technique shows preference for the similarity to an ideal solution, which tries to select an alternative that is closest to the ideal solution and simultaneously farthest from the anti-ideal solution. In this technique, the decision matrix is first normalized using vector normalization, and the ideal and anti-ideal solutions are identified within the normalized decision matrix.

TOPSIS was developed in 1981 by Hwang and Yoon, and it selects alternatives having the shortest distance from the positive ideal solution and the farthest distance from the negative ideal solution [21]. It is a multiple criteria method for identifying solutions from a finite set of alternatives.
The optimal solution should have the shortest distance from the positive ideal solution and the farthest from the negative ideal solution [22]. The TOPSIS method introduces an aggregating function, including the distances from the ideal point and from the negative-ideal point without considering their relative importance. However, the reference point could be a major concern in decision making, and it should be as close as possible to the ideal solution $[20,22]$.

3.4. Elimination and Choice Expressing Reality (ELECTRE). ELECTRE was developed in 1991 by Roy and colleagues at the SEMA Consultancy Company. Several versions of this method have been developed since (ELECTRE I, ELECTRE II, ELECTRE III, ELECTRE IV, ELECTRE IS, and ELECTRE TRI (ELECTRE Tree)). ELECTRE consists of two sets of parameters: the importance coefficient and the veto thresholds [21].

This method falls in the class of outranking MCDM methods. In comparison with the previously discussed methods, this method is computationally intricate: the simplest variant of ELECTRE involves up to 10 steps. It performs a pairwise comparison between the alternatives in order to determine their outranking relationships. These relationships are then used to identify and eliminate alternatives that are dominated by others, yielding a smaller set of alternatives.

The ELECTRE method handles discrete criteria that are both quantitative and qualitative in nature, providing complete ordering of the alternatives. Alternatives are preferred over most of the criteria and depend on concordance, discordance indices, and threshold values and graphs of relationships. These graphs are used in an iterative procedure to obtain the ranking of alternatives $[20,22]$.

3.5. Preference Ranking Organization METHod of Enrichment Evaluations (PROMETHEE). PROMETHEE was developed in the mid-1980s by Brans and Vincke. It is an improved 
form of the outranking method ELECTRE, but it differs from ELECTRE in the pairwise comparison stage. Whereas both PROMETHEE and ELECTRE determine whether one particular alternative is better than another, PROMETHEE additionally considers the degree to which it is better, using this piece of information to eliminate dominated alternatives and to identify nondominated or least dominated alternatives. PROMETHEE ranks the alternatives and is easier to use and less complex than ELECTRE [22].

3.6. Decision-Making Trial and Evaluation Laboratory (DEMATEL). Gabus \& Fontela developed DEMATEL in 1973 at the Geneva Research Centre of the Battelle Memorial Institute. This method represents factors as interrelationships among criteria. Hence, DEMATEL is a complete method for building a structural model involving associations of complex factors. It organizes relationships between the elements within a system using numerical representations of the power of influence [24]. This method has been applied successfully in a diversity of situations, such as developing marketing strategies, developing control systems, solving safety problems, and group decision making [23].

3.7. Grey Relational Analysis (GRA). The grey system theory proposed by Deng (1982) has been widely applied in many fields. The term "grey" interpreted as a color is intended to suggest the amount of known information in control theory. GRA, derived from grey system theory, is particularly useful when dealing with poor, incomplete, and uncertain information. It is suitable for solving problems with complex interrelationships between factors and variables, and it has been successfully applied to solve a variety of MADM problems. The main advantages of GRA are the fact that the results are based on original data and that calculation is straightforward and simple [25].

3.8. VIKOR. VIKOR, also known as the compromise ranking method, is an effective tool in multicriteria decision making. The acronym is derived from the word ViseKriterijumska Optimizacija I Kompromisno Resenje. Its multicriteria ranking index is based on a measure of "closeness" to the "ideal" solution. This method was introduced by Opricovic in 2004 for optimization and compromise evaluation in dynamic and complex processes.

VIKOR employs linear normalization, but the normalized values do not depend upon the evaluation unit of a criterion. An aggregating function balances the distance from the ideal solution between individual and ideal satisfaction [22]. It is an efficient MCDA technique for ranking, sorting, and then selecting from a set of conflicting alternatives [26].

3.9. Fuzzy. In 1965, Zadeh proposed fuzzy set theory, which has been extensively applied to model the ambiguities of human judgment. It also effectively resolves uncertainties in available information for multiple criteria decision making. A fuzzy MCDA model is used to evaluate selected alternative criteria by using decision pools. The suitability of replacements versus criteria and the significance weights of criteria are evaluated in terms of linguistic values represented by fuzzy numbers [27]. In the fuzzy set, linguistic variables are used to describe fuzzy terms that are then used to map the linguistic variables to numerical variables. The truth values of Boolean logic are replaced with unit intervals in the decisionmaking process [26].

3.10. Goal Programming. In 1955, Charnes first employed goal programming as an MODM tool. Goal programming is an extension of linear programming used to solve problems containing multiple, usually conflicting, objects. It is an optimization procedure for handling multiple conflicting objective measures. It is widely used in multicriteria decision making to combine the logic of optimization with mathematical programming in order to make decisions fulfilling several objectives [28].

3.11. Data Envelopment Analysis (DEA). Data envelopment analysis (DEA) is a mathematical programming technique used for evaluating the competence of an observation relative to a set of similar observations [29]. DEA concentrates on measuring the efficiency of multiple decision-making units in an environment with multiple inputs and outputs. Charnes first introduced DEA in 1978 for performance measurement and then later presented a comprehensive theoretical framework. DEA is a nonparametric method for operations research. There have been several applications of DEA in different industries to measure the impact of a multicriteria decision-making system [21]. To aid the understanding of the general reader, several applied techniques, definitions, and aspects are presented in Table 1.

\section{Cloud Service Selection Based on MCDA}

MCDA is a well-established area within the field of operations research, and it has proven its effectiveness in addressing different complex real-world decision-making problems. In [20], a comparative study is presented involving an infrastructure-as-a-service cloud, using MCDA techniques to select the best service based on performance measurements made by a third party monitoring service against five different criteria. Two prominent classes of MCDA are used, multiattribute utility theory (MAUT) and Outranking. Based upon several types, methods, and categories, we derived a taxonomy for multioptions and multicriteria decision making. The results show that MCDA techniques are indeed effective and can be used for cloud service selection but that different techniques do not select the same service. Hence, more work is needed to identify the most effective MCDA method for cloud selection using an extended data set and much broader criteria. However, these results do reveal that TOPSIS and both outranking methods (ELECTRE and PROMETHEE) are more suitable for this purpose. If the number of available services is very large, then TOPSIS is appropriate because of its computational simplicity. The outranking methods are 
TABLE 1: Summary of MCDA techniques and capabilities.

\begin{tabular}{|c|c|c|c|}
\hline Name & Objective & Criteria/approach & Author and year \\
\hline Goal programming & $\begin{array}{l}\text { Application of linear programming to solve } \\
\text { problems relating to multiple and conflicting } \\
\text { objects }\end{array}$ & $\begin{array}{l}\text { Combination of the logic of optimization } \\
\text { with mathematical programming }\end{array}$ & Charnes et al. (1955) \\
\hline Fuzzy & $\begin{array}{l}\text { Evaluation of significance weights in terms of } \\
\text { linguistic values represented by fuzzy numbers }\end{array}$ & $\begin{array}{l}\text { Linguistic variables used to describe fuzzy } \\
\text { terms that are then mapped to numerical } \\
\text { variables }\end{array}$ & Zadeh (1965) \\
\hline DEMATEL & $\begin{array}{l}\text { Construction of a structural model involving } \\
\text { associations of complex factors }\end{array}$ & $\begin{array}{l}\text { Numerical contextual relations among the } \\
\text { elements representing the power of influence }\end{array}$ & $\begin{array}{c}\text { Gabus and Fontela } \\
\text { (1973) }\end{array}$ \\
\hline DEA & $\begin{array}{l}\text { Evaluation of the competence of an observation } \\
\text { relative to a set of similar observations }\end{array}$ & Mathematical programming & Charnes (1978) \\
\hline AHP & $\begin{array}{l}\text { Pairwise comparison of attributes structured in a } \\
\text { hierarchal relationship }\end{array}$ & $\begin{array}{l}\text { Useful technique for hierarchical } \\
\text { relationship criteria }\end{array}$ & $\begin{array}{c}\text { Thomas L. Saaty } \\
(1980)\end{array}$ \\
\hline PROMETHEE & $\begin{array}{l}\text { Similar to ELECTRE but differing in the } \\
\text { pairwise comparison stage }\end{array}$ & $\begin{array}{l}\text { Considers the degree to which one } \\
\text { alternative differs from another }\end{array}$ & $\begin{array}{c}\text { Brans and Vincke } \\
\text { (1980) }\end{array}$ \\
\hline TOPSIS & $\begin{array}{l}\text { Selection of an alternative simultaneously the } \\
\text { closest to the ideal solution and the farthest from } \\
\text { the anti-ideal solution }\end{array}$ & $\begin{array}{l}\text { Close to ideal but the farthest from } \\
\text { anti-ideal }\end{array}$ & $\begin{array}{c}\text { Hwang and Yoon } \\
\text { (1981) }\end{array}$ \\
\hline GRA & $\begin{array}{l}\text { Solution of problems with complex } \\
\text { interrelationships between factors and variables }\end{array}$ & Based on grey system theory & Deng (1982) \\
\hline ELECTRE & $\begin{array}{l}\text { Pairwise comparison among alternatives used to } \\
\text { identify and eliminate alternatives dominated by } \\
\text { other alternatives }\end{array}$ & $\begin{array}{l}\text { Checks only whether one alternative is } \\
\text { better or worse than the other }\end{array}$ & Roy (1991) \\
\hline ANP & $\begin{array}{l}\text { More general representation of interrelationships } \\
\text { among decision levels and attributes }\end{array}$ & $\begin{array}{l}\text { Unidirectional relationships with } \\
\text { dependence and feedback instead of } \\
\text { hierarchy }\end{array}$ & $\begin{array}{l}\text { Thomas L. Saaty } \\
\text { (1996) }\end{array}$ \\
\hline VIKOR & $\begin{array}{l}\text { Ranking of compromises representing indices } \\
\text { derived from a measure of "closeness" to the } \\
\text { "ideal" solution }\end{array}$ & Employs linear normalization & Opricovic (2004) \\
\hline
\end{tabular}

better in scenarios with a small number of alternatives but a large number of criteria.

4.1. Service Selection by AHP. AHP was proposed in order to solve this problem by using a hierarchical structure and systematization [30]. In AHP, a ratio is assigned to each pairwise comparison between issues for each criterion in a hierarchy and also between the criteria themselves. Pairwise comparison results are then organized into a hierarchy with a weight assigned to each criterion, providing both qualitative and quantitative measures.

AHP is used by decision makers in order to make more informed decisions regarding their investment in various technologies. AHP is a multiobjective, multicriteria decisionmaking approach, employing pairwise comparison to derive a range of preferences from a set of alternatives. This is achieved by determining the responsiveness of the selection process to rapidly changing business rules and criteria. AHP transforms the decision-making process from a subjective judgment into an objective determination. A sophisticated formal mathematical decision model supporting the selection of cloud computing services in a multisourcing scenario is presented in [31]. To select appropriate cloud computing services offered by different providers, these authors consider cost and risk factors in the decision-making process. By employing AHP, the risks are considered when implementing the model in a sustainable comprehensive decision-making approach. This method was validated by a simulation study and by considering realistic scenarios.

A model for applying AHP to task-oriented resource allocation in a cloud computing environment is proposed in [32]. The tasks are compared pairwise according to network bandwidth, task completion time, task costs, and task reliability and then weighted with AHP. Resources are then allocated accordingly. The reciprocal comparison matrix and the induced bias matrix are used to identify inconsistent elements and to improve the consistency ratio. In [33], SaaS products are offered in a cloud computing environment that uses AHP to prioritize product features based on an expert scoring system. In [34], SLA and QoS are applied to distributed resource management in the cloud. AHP enables the system to automatically recognize changes in the dynamic environment, making decisions according to available resources and user requirements.

In [35], a novel AHP-based consumer centered cloud service selection method is introduced that specifically is applied to a medical service cloud environment. This consumercentered service selection mainly considers the preferences of 
individual and multiple users. The authors introduce cloud services decision making (CSDM) for making reasonable cloud service selections that are already applicable to other areas for which a similar information model is available [35].

Although AHP is an effective decision-making tool, disadvantages such as decision maker subjectivity can yield uncertainties when determining pairwise comparisons. In [36], fuzzy AHP was proposed to overcome some of these disadvantages. This method allows experts to use fuzzy ratios in place of exact ratios. However, it is often difficult for the expert to exactly quantify his or her opinion of a number within the interval $[0,1]$. Therefore, it is more suitable to represent this degree of certainty with an interval [37]. The membership values expressed in this interval value can better fit real-world situations. Therefore, IVFs are suitable to represent the fuzziness of the membership value of their opinions. They combined IVFs with fuzzy AHP to propose a new method to determine the fuzzy weights in interval-valued fuzzy numbers. A fuzzy set can be mathematically expressed by assigning to each possible element in the universe of discourse a value representing its grade of membership in the fuzzy set. In [38], the proposed method has several steps, and IVFs are used to establish the sequence of the computation procedure: first establish the hierarchical structure and obtain expert judgment from the fuzzy weights by using IVF AHP. Then compute the alternative performance rating and integrate it with weight criteria, and finally, rank the alternatives.

Although fuzzy set theory can be applied to decisionmaking problems possessing a degree of uncertainty, the resulting subjective judgment is always somewhat vague. Fuzzy AHP is applied to compute the fuzzy weights of each criterion based on intervalued fuzzy sets (IVFs). In [38], tuples were employed to express the performance ratings of all variables and to determine the ranking order of possible alternatives according to the preference matrix. In the real world, decision-making problems are fraught with uncertainty. Because the subjective judgments of decision makers are always vague, linguistic variables and intervalvalued fuzzy sets are suitable for representing the fuzziness of membership values. Fuzzy AHP was applied to compute the fuzzy weights of each criterion based on interval-valued fuzzy set/linguistic variable tuples to express the performance ratings of all alternatives. The alternatives were then ranked in accordance with the preference matrix. This method can provide the decision maker with greater flexibility in expressing his or her subjective judgment with respect to each alternative [38].

In MCC, one of the aims is to select the optimal cloud path between certain classes of clouds that provide the same service in order to offload particular computation tasks [32]. Because many criteria need to be considered, such as speed, bandwidth, price, security, and availability, a multiple criteria decision analysis approach is required to make correct decisions. Here, AHP is used to determine the weights of the cloud path selection criteria, while fuzzy TOPSIS is used to perform the numerical analysis for ranking.
4.2. Service Selection Based on TOPSIS Method. Cloud service selection is a multiple criteria group decision-making (MCDM) problem. The technique for order preference by similarity (OPS) to an ideal solution (TOPSIS) can assist service consumers and providers by analyzing available services using fuzzy opinions. In [39], the authors find that a set of predetermined linguistic variables can be parameterized by triangular fuzzy numbers, which can then be used to evaluate the weights of different criteria and the ratings of alternate web services. They describe a fuzzy TOPSIS numerical example to demonstrate computational efficiency.

Web services are tremendously interactive software components that can be published, located, and invoked practically anywhere on the Web. The increasing number of Web services available raises new challenges related to service discovery, selection, and composition. Machine-readable rich representations of service properties, capabilities, and characteristics can be exploited by reasoning mechanisms to support automated discovery [40]. Present discovery techniques do not consider the user's preferences and expectations. A semiordered preference model is introduced in [41] for content-based service discovery. The aim here is to assist service providers and customers in discovering services that match their expectations and preferences. A fuzzy model for the selection of QoS-aware web services, prioritizing customer preferences, is described in [42].

TOPSIS, described in [42], is a well-known multiple criteria decision-making (MCDM) method. It determines the shortest distance from the positive ideal solution (PIS) and the farthest distance from the negative ideal solution (NIS) in order to select the best alternative. TOPSIS is a popular MCDA technique because of its (1) theoretical rigor, (2) ability to represent the human rationale during selection, and (3) prominence in solving traversal rank. Fuzzy TOPSIS methods are now popular for dealing with imprecise information. In [19], fuzzy TOPSIS was employed to assess the selection of web services. Triangular fuzzy numbers are used to represent linguistic variables as the weights of criteria and as the ratings of web services and can be converted into crisp numbers. This conversion performed using the graded mean integration representation method. The triangular fuzzy number is then used to obtain the PIS and the NIS. Therefore, the fuzzy TOPSIS procedure is efficient, and the computational complexity in the decisionmaking process is reduced.

In [43], a new user centric service-oriented modeling approach is described, which integrates Fuzzy TOPSIS and service component architecture (SCA). Web service selection and composition are effectively satisfied by a group of service consumers' subjective requirements and preferences in a dynamic environment. This method can translate a group of customers' fuzzy requirements into service requirements and model different levels of hardware and software as services in order to satisfy these requirements. A simulated environment represented by $8 * 8$ LED matrices on a circuit board, corresponding to an office with different appliances, was used to demonstrate dynamic service selection. Using Fuzzy TOPSIS, the simulated computational efficiency of this system was very high. 
TABLE 2: Summary of different applied multicriteria methods for cloud service selection.

\begin{tabular}{|c|c|c|c|}
\hline MCDA technique & Aspects & Attributes & Reference \\
\hline AHP & $\begin{array}{l}\text { Consumer-centered service selection, especially } \\
\text { for medical services }\end{array}$ & User preference & {$[35]$} \\
\hline TOPSIS & $\begin{array}{l}\text { QoS-based multiple service selection with fuzzy } \\
\text { options }\end{array}$ & Linguistic variable triangular fuzzy numbers & {$[39]$} \\
\hline PROMETHEE & $\begin{array}{l}\text { Dynamic autonomous resource, management, } \\
\text { and scalability }\end{array}$ & Suitable for large data centers & {$[49]$} \\
\hline AHP & Fuzzy AHP with IVFs & 2-tuple linguistic variables & {$[38]$} \\
\hline Fuzzy & $\begin{array}{l}\text { Fuzzy logic-based resource evaluation technique } \\
\text { for the DSPR framework }\end{array}$ & Fuzzy inference engine for resource evaluation. & {$[45]$} \\
\hline AHP & $\begin{array}{l}\text { Identifying the scalability gain of enhanced } \\
\text { agility in the selection process }\end{array}$ & Pairwise comparison & {$[50]$} \\
\hline Fuzzy & $\begin{array}{l}\text { Response time-based fuzzy control for the } \\
\text { allocation of virtualized cloud resources }\end{array}$ & $\begin{array}{l}\text { Adaptive output amplification and flexible rule } \\
\text { selection }\end{array}$ & {$[44]$} \\
\hline Fuzzy TOPSIS & $\begin{array}{l}\text { New user centric service-oriented modeling } \\
\text { approach in SCA. }\end{array}$ & Computational efficiency & {$[43]$} \\
\hline AHP & $\begin{array}{l}\text { Decision model to support cloud computing } \\
\text { services }\end{array}$ & Costs and risk factors & {$[31]$} \\
\hline $\begin{array}{l}\text { Fuzzy DNAP and } \\
\text { fuzzy VIKOR }\end{array}$ & $\begin{array}{l}\text { Exploring interrelationships among criteria } \\
\text { related to operations }\end{array}$ & Solves interdependence and feedback problems. & {$[48]$} \\
\hline $\begin{array}{l}\text { AHP and fuzzy } \\
\text { TOPSIS }\end{array}$ & $\begin{array}{l}\text { Optimal cloud path among class of clouds to } \\
\text { perform offloaded computation tasks }\end{array}$ & $\begin{array}{l}\text { Speed, bandwidth, price, security, and } \\
\text { availability }\end{array}$ & {$[32]$} \\
\hline AHP & Distributed resource management & Considers SLA and QoS & [34] \\
\hline ANP & $\begin{array}{l}\text { QoS measuring method for cloud service } \\
\text { architecture }\end{array}$ & A supermatrix is employed for calculation & {$[46]$} \\
\hline Fuzzy VIKOR & $\begin{array}{l}\text { Assesses cloud service trustworthiness using a } \\
\text { hybrid model }\end{array}$ & Weight-based preferences & {$[26]$} \\
\hline IVF and VIKOR & Decision analysis model for service selection & Linguistic variables & {$[47]$} \\
\hline AHP & Task-oriented resource allocation & Bandwidth, task costs, and time & {$[51]$} \\
\hline
\end{tabular}

4.3. Other Methods of Service Selection. A response timebased fuzzy control approach has been proposed for allocation of virtualized resources using a self-tuning fuzzy controller with adaptive output amplification and flexible rule selection. Based on the fuzzy controller, a two-layer QoS provisioning framework, DynaQoS was designed to support adaptive multiobjective resource allocation and service differentiation [44]. The dynamic service placement and replication (DSPR) was designed to manage services in a distributed environment by repetitively searching for the best combination of distributed machines from a resource pool until the working group that best satisfies the requirements of the service is found. DSPR introduces a fuzzy inference engine to perform resource evaluation. The effectiveness of this engine is compared with other existing resource evaluation techniques such as rule-based, constraint-based, and utility-based techniques [45]. For service-oriented architectures (SOAs), a QoS measuring method for enterprise cloud service architecture using ANP was developed through research on enterprise cloud service architecture. The supermatrix is used to calculate the relative superiority of each metric element. QoS-ANP can be extended to rank infinite alternatives based on QoS optimization and can also be used to analyze trade-off decisions with multiattributes [46].
Several applied multicriteria cloud service selection methods are shown in Table 2.

4.4. Mixed/Combined Approach. In [43], a new approach for dynamic autonomous resource management and scalability in cloud computing was introduced. In this approach, distributed resource management architecture is adopted for Autonomous Node Agents that are tightly coupled with physical machines in a data center. The PROMETHEE method in particular is employed in MCDA. Simulation results validate this approach's efficiency in terms of scalability, feasibility, and flexibility. It is especially suitable for large data centers compared to centralized approaches, as less migration is needed when applying new configurations. The ease of adding or removing criteria and weights in order to change the configuration makes this a particularly flexible approach.

Evaluating the trustworthiness of a Cloud Service suffers from great uncertainty and complexity. To address this issue, a novel hybrid fuzzy multicriteria group decision-making method, based on a combination of fuzzy set and modified VIKOR methods, was proposed. It addresses various types of conflicting and incommensurable trust criteria and selects appropriate weight-based preferences in order to make a suitable decision [26]. 
A wide range of criteria is used to assess the quality of cloud computing services. A hybrid fuzzy MCDM approach combining fuzzy DEMATEL, fuzzy DANP, and fuzzy VIKOR has been used to improve service levels and meet user needs in fuzzy environments. This approach solves interdependence and feedback problems in the mobile communications industry and for related value-added service content providers by exploring interrelationships among criteria related to operations [47]. It finds an optimal cloud path selection in an optimal cloud from among a certain class of clouds that provide the same service for offloading the computation tasks. AHP and the TOPSIS in a fuzzy environment have been proposed to decide which cloud is the most suitable for offloading. Hence, AHP is employed to determine the weights for the criteria during cloud-path selection, and fuzzy TOPSIS is used for ranking the cloud services. A numerical analysis is performed to evaluate the model [32].

The selection of cloud service providers is a multicriteria decision-making (MCDM) problem. The cloud service providers with the best technology are not always suitable for a given enterprise. VIKOR is often used to solve these dilemmas. Further complicating matters, incorporating expert opinion always introduces subjectivity and vagueness to the decision-making process. Experts can use linguistic variables to express their opinions, and these variables can be used to define interval-valued fuzzy sets. A decision analysis model combining interval-valued fuzzy sets and VIKOR (IVFVIKOR) is described in [48] that evaluates and selects the suitable cloud service provider. A numerical example is used to illustrate the method's computational processing.

\section{Conclusion}

In this study, we focus on the service selection for cloud computing in multicriteria decision-making situations. We describe the MCDA types and characteristics and present a taxonomic categorization. We compare several methods by synthesizing and reviewing the present literature. Several real-world examples with current applications of different methods are provided. Hence, MCDA has a great effect on and importance in multicriteria decision-making scenarios. We thus summarize several of the advantages and disadvantages, and we present several applications of these MCDA methods in the selection of cloud services. In addition, multicriteria applied methods are summarized and compiled in a comprehensive manner that can be applicable in other research fields. Moreover, different MCDA methods and their unique features are presented and compared, which will aid new researchers in selecting research directions. We envision that this study could be extended for intercloud service selections and for mobile cloud computing.

\footnotetext{
Abbreviations

AHP: Analytic hierarchy process

ANP: Analytic network process

CC: Cloud computing

CWS: Component web services
}

DEA: Data envelopment analysis

DEMATEL: Decision-making trial and evaluation laboratory

DSPR: Dynamic service placement and replication

ELECTRE: Elimination and choice expressing reality

GA: Genetic algorithm

GRA: Grey relational analysis

IVF: Intervalued fuzzy

IVS: Item-based vector similarity

MAUT: $\quad$ Multiple attribute utility theory

MADM: $\quad$ Multiattribute decision making

MCC: $\quad$ Mobile cloud computing

MCDA: Multicriteria decision analysis

MCDM: $\quad$ Multicriteria decision making

MCMP: $\quad$ Multicriteria mathematical problem

MCSP: Multicriteria selection problem

MODM: $\quad$ MultiObjective decision making

PROMETHEE: Preference ranking organization

QoS:

SLA:

SAW:

SOA:

SVD:

TOPSIS: method of enrichment evaluations

Quality of service

Service level agreement

Simple additive weighting

Service oriented architecture

Singular value decomposition

Technique for order preference by similarity (OPS) to an ideal solution (TOPSIS)

UDDI: Universal discovery description and integration

VIKOR: $\quad$ ViseKriterijumska Optimizacija I

WS:

WSCT: Web service composition tree.

\section{Conflict of Interests}

The authors declare that there is no conflict of interests regarding the publication of this paper.

\section{Acknowledgment}

This work is fully funded by the Malaysian Ministry of Higher Education under the University of Malaya High Impact Research Grant UM.C/HIR/MOHE/FCSIT/03.

\section{References}

[1] R. Buyya, C. S. Yeo, S. Venugopal, J. Broberg, and I. Brandic, "Cloud computing and emerging IT platforms: vision, hype, and reality for delivering computing as the 5th utility," Future Generation Computer Systems, vol. 25, no. 6, pp. 599-616, 2009.

[2] S. Abolfazli, Z. Sanaei, A. Gani, F. Xia, and L. T. Yang, "Rich mobile applications: genesis, taxonomy, and open issues," Journal of Network and Computer Applications, 2013.

[3] N. Phaphoom, X. Wang, and P. Abrahamsson, "Foundations and technological landscape of cloud computing," ISRN Software Engineering, vol. 2013, Article ID 782174, 31 pages, 2013. 
[4] M. Whaiduzzaman, M. Sookhak, A. Gani, and R. Buyya, "A survey on vehicular cloud computing," Journal of Network and Computer Applications, 2013.

[5] H. Liang, T. Xing, L. X. Cai, D. Huang, D. Peng, and Y. Liu, "Adaptive computing resource allocation for mobile cloud computing," International Journal of Distributed Sensor Networks, vol. 2013, Article ID 181426, 14 pages, 2013.

[6] Z. Sanaei, S. Abolfazli, A. Gani, and R. Buyya, "Heterogeneity in mobile cloud computing: taxonomy and open challenges," IEEE Communications Surveys \& Tutorials, no. 99, pp. 1-24, 2013.

[7] M. Shiraz, A. Gani, R. H. Khokhar, and R. Buyya, "A review on distributed application processing frameworks in smart mobile devices for mobile cloud computing," IEEE Communications Surveys \& Tutorials, vol. 15, no. 3, pp. 1294-1313, 2013.

[8] X. Wang, X. Liu, L. Fan, and X. Jia, "A decentralized virtual machine migration approach of data centers for cloud computing," Mathematical Problems in Engineering, vol. 2013, Article ID 878542, 10 pages, 2013.

[9] S. Abolfazli, Z. Sanaei, E. Ahmed, A. Gani, and R. Buyya, "Cloud-based augmentation for mobile devices: motivation, taxonomies, and open challenges," IEEE Communications Surveys \& Tutorials, no. 99, pp. 1-32, 2013.

[10] M. Shiraz, M. Whaiduzzaman, and A. Gani, "A study on anatomy of smartphone," Computer Communication \& Collaboration, vol. 1, pp. 24-31, 2013.

[11] M. K. Nasir and M. Whaiduzzaman, "Use of cell phone density for Intelligent Transportation System (ITS) in Bangladesh," Jahangirnagar University Journal of Information Technology, vol. 1, pp. 49-54, 2012.

[12] M. Shiraz, S. Abolfazli, Z. Sanaei, and A. Gani, "A study on virtual machine deployment for application outsourcing in mobile cloud computing," The Journal of Supercomputing, vol. 63, no. 3, pp. 946-964, 2013.

[13] A. Goscinski and M. Brock, "Toward dynamic and attribute based publication, discovery and selection for cloud computing," Future Generation Computer Systems, vol. 26, no. 7, pp. 947-970, 2010.

[14] S. K. Garg, S. Versteeg, and R. Buyya, "A framework for ranking of cloud computing services," Future Generation Computer Systems, vol. 29, no. 4, pp. 1012-1023, 2013.

[15] C.-H. Chen, H.-F. Lin, H.-C. Chang, P.-H. Ho, and C.-C. Lo, "An analytical framework of a deployment strategy for cloud computing services: a case study of academic websites," Mathematical Problems in Engineering, vol. 2013, Article ID 384305, 14 pages, 2013.

[16] J. Figueira, S. Greco, and M. Ehrgott, Multiple Criteria Decision Analysis: State of the Art Surveys, vol. 78, Springer, 2005.

[17] X.-F. Wang, J.-Q. Wang, and S.-Y. Deng, "A method to dynamic stochastic multicriteria decision making with log-normally distributed random variables," The Scientific World Journal, vol. 2013, Article ID 202085, 8 pages, 2013.

[18] Umm-e-Habiba and S. Asghar, "A survey on Multi-criteria decision making approaches," in Proceedings of the International Conference on Emerging Technologies (ICET '09), pp. 321-325, October 2009.

[19] S. Yassa, R. Chelouah, H. Kadima, and B. Granado, "Multiobjective approach for energy-aware workflow scheduling in cloud computing environments," The Scientific World Journal, vol. 2013, Article ID 350934, 13 pages, 2013.

[20] Z. ur Rehman, O. K. Hussain, and F. K. Hussain, "Iaas cloud selection using MCDM methods," in Proceedings of the 19th IEEE International Conference on e-Business Engineering (ICEBE '12), pp. 246-251, 2012.

[21] Y. Mohammadshahi, "A state-of-art survey on TQM applications using MCDM techniques," Decision Science Letters, vol. 2, no. 3, pp. 125-134, 2013.

[22] J. R. S. Cristóbal, "Multi-criteria decision-making in the selection of a renewable energy project in Spain: the Vikor method," Renewable Energy, vol. 36, no. 2, pp. 498-502, 2011.

[23] Y. P. O. Yang, H. M. Shieh, J. D. Leu, and G. H. Tzeng, "A novel hybrid MCDM model combined with DEMATEL and ANP with applications," International Journal of Operations Research, vol. 5, pp. 160-168, 2008.

[24] G. Büyüközkan and G. Ifi, "A novel hybrid MCDM approach based on fuzzy DEMATEL, fuzzy ANP and fuzzy TOPSIS to evaluate green suppliers," Expert Systems with Applications, vol. 39, no. 3, pp. 3000-3011, 2012.

[25] G.-W. Wei, "Gray relational analysis method for intuitionistic fuzzy multiple attribute decision making," Expert Systems with Applications, vol. 38, no. 9, pp. 11671-11677, 2011.

[26] H. M. Alabool and A. K. Mahmood, “Trust-based service selection in public cloud computing using fuzzy modified VIKOR method," Australian Journal of Basic and Applied Sciences, vol. 7, no. 9, pp. 211-220, 2013.

[27] M. Jaiganesh and A. V. A. Kumar, "B3: fuzzy-based data center load optimization in cloud computing," Mathematical Problems in Engineering, vol. 2013, Article ID 612182, 11 pages, 2013.

[28] R. K. Pati, P. Vrat, and P. Kumar, "A goal programming model for paper recycling system," Omega, vol. 36, no. 3, pp. 405-417, 2008.

[29] W.-C. Chen and A. L. Johnson, "A unified model for detecting efficient and inefficient outliers in data envelopment analysis," Computers \& Operations Research, vol. 37, no. 2, pp. 417-425, 2010.

[30] T. L. Saaty, "How to make a decision: the analytic hierarchy process," European Journal of Operational Research, vol. 48, no. 1, pp. 9-26, 1990.

[31] B. Martens and F. Teuteberg, "Decision-making in cloud computing environments: a cost and risk based approach," Information Systems Frontiers, vol. 14, no. 4, pp. 871-893, 2012.

[32] H. Wu, Q. Wang, and K. Wolter, "Methods of cloud-path selection for offloading in mobile cloud computing systems," in Proceedings of the 4th IEEE International Conference on Cloud Computing Technology and Science (CloudCom '12), pp. 443448, 2012.

[33] M. Godse and S. Mulik, "An approach for selecting Software-asa-Service (SaaS) product," in Proceedings of the IEEE International Conference on Cloud Computing (CLOUD '09), pp. 155158, September 2009.

[34] S. Khaddaj, "Cloud computing: service provisioning and user requirements," in Proceedings of the 11th International Symposium on Distributed Computing and Applications to Business, Engineering \& Science (DCABES '12), pp. 191-195, 2012.

[35] M. Sun, T. Zang, X. Xu, and R. Wang, "Consumer-centered cloud services selection using AHP," in Proceedings of the International Conference on Service Sciences (ICSS '13), pp. 1-6, Shenzhen, China, 2013.

[36] J. J. Buckley, T. Feuring, and Y. Hayashi, "Fuzzy hierarchical analysis revisited," European Journal of Operational Research, vol. 129, no. 1, pp. 48-64, 2001.

[37] B. Ashtiani, F. Haghighirad, A. Makui, and G. A. Montazer, "Extension of fuzzy TOPSIS method based on interval-valued 
fuzzy sets," Applied Soft Computing Journal, vol. 9, no. 2, pp. 457461, 2009.

[38] C.-T. Chen and K.-H. Lin, "A decision-making method based on interval-valued fuzzy sets for cloud service evaluation," in Proceedings of the 4th International Conference on New Trends in Information Science and Service Science (NISS '10), pp. 559564, May 2010.

[39] C.-C. Lo, D.-Y. Chen, C.-F. Tsai, and K.-M. Chao, "Service selection based on fuzzy TOPSIS method," in Proceedings of the 24th IEEE International Conference on Advanced Information Networking and Applications Workshops (WAINA '10), pp. 367372, April 2010.

[40] F. Casati, S. Ilnicki, L. Jin, V. Krishnamoorthy, and M.-C. Shan, "Adaptive and dynamic service composition in eFlow," in Advanced Information Systems Engineering, B. Wangler and L. Bergman, Eds., vol. 1789 of Lecture Notes in Computer Science, pp. 13-31, 2000.

[41] C.-L. Huang, C.-C. Lo, P. Wang, K.-M. Chao, and Y. Li, "Applying semi-order preference model in content-based service discovery," International Journal of Electronic Business Management, vol. 5, no. 1, pp. 48-58, 2007.

[42] P. Wang, K.-M. Chao, and C.-C. Lo, "On optimal decision for QoS-aware composite service selection," Expert Systems with Applications, vol. 37, no. 1, pp. 440-449, 2010.

[43] D.-Y. Cheng, K.-M. Chao, C.-C. Lo, and C.-F. Tsai, "A user centric service-oriented modeling approach," World Wide Web, vol. 14, no. 4, pp. 431-459, 2011.

[44] J. Rao, Y. Wei, J. Gong, and C.-Z. Xu, "DynaQoS: modelfree self-tuning fuzzy control of virtualized resources for QoS provisioning," in Proceedings of the 19th IEEE International Workshop on Quality of Service (IWQoS '11), pp. 1-9, June 2011.

[45] B. Y. Ooi, H. Y. Chan, and Y.-N. Cheah, "Resource selection using fuzzy logic for dynamic service placement and replication," in Proceedings of the IEEE Region 10 Conference (TENCON '11), pp. 128-132, November 2011.

[46] M. Wang and Y. Liu, "QoS evaluation of cloud service architecture based on ANP," in Proceedings of the International Symposium on the Analytic Hierarchy Process, 2013.

[47] C.-H. Su, G.-H. Tzeng, and H.-L. Tseng, "Improving cloud computing service in fuzzy environment-combining fuzzy DANP and fuzzy VIKOR with a new hybrid FMCDM model," in Proceedings of the International Conference on Fuzzy Theory and it's Applications (iFUZZY '12), pp. 30-35, 2012.

[48] C.-T. Chen, W.-Z. Hung, and W.-Y. Zhang, "Using intervalvalued fuzzy VIKOR for cloud service provider evalution and selection," in Proceedings of the International Conference on Business and Information (BAI '13), Bali, Indonesia, July 2013.

[49] Y. O. Yazir, C. Matthews, R. Farahbod et al., "Dynamic resource allocation in computing clouds using distributed multiple criteria decision analysis," in Proceedings of the IEEE $3 \mathrm{rd}$ International Conference on Cloud Computing (CLOUD '10), pp. 91-98.

[50] E. Ristova and G. Valentina, "AHP methodology and selection of an advanced information technology due to PLM software adoption," in Proceedings of the 15th International Scientific Conference on Industrial Systems, 2011.

[51] D. Ergu, G. Kou, Y. Peng, Y. Shi, and Y. Shi, "The analytic hierarchy process: task scheduling and resource allocation in cloud computing environment," The Journal of Supercomputing, vol. 64 , pp. 835-848, 2013. 

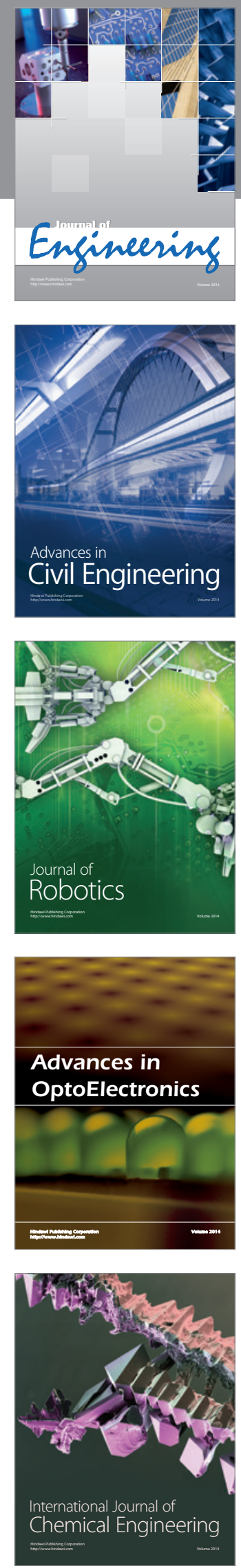

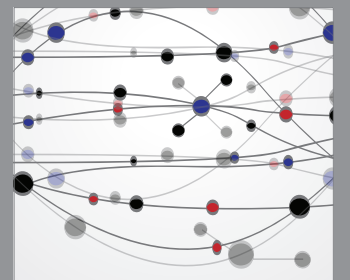

The Scientific World Journal
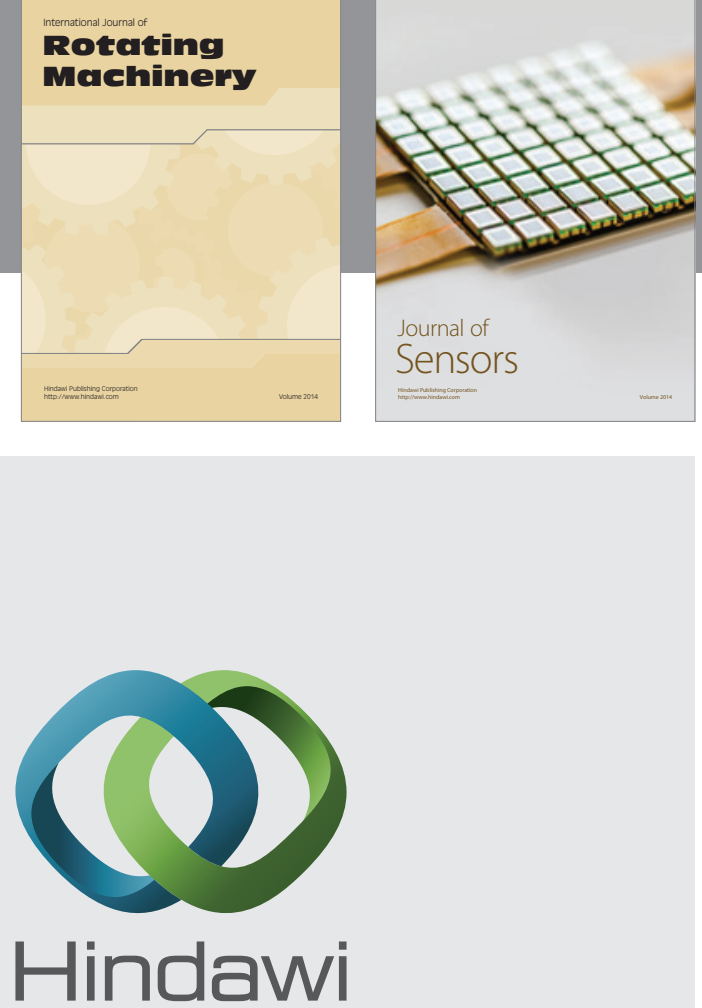

Submit your manuscripts at http://www.hindawi.com
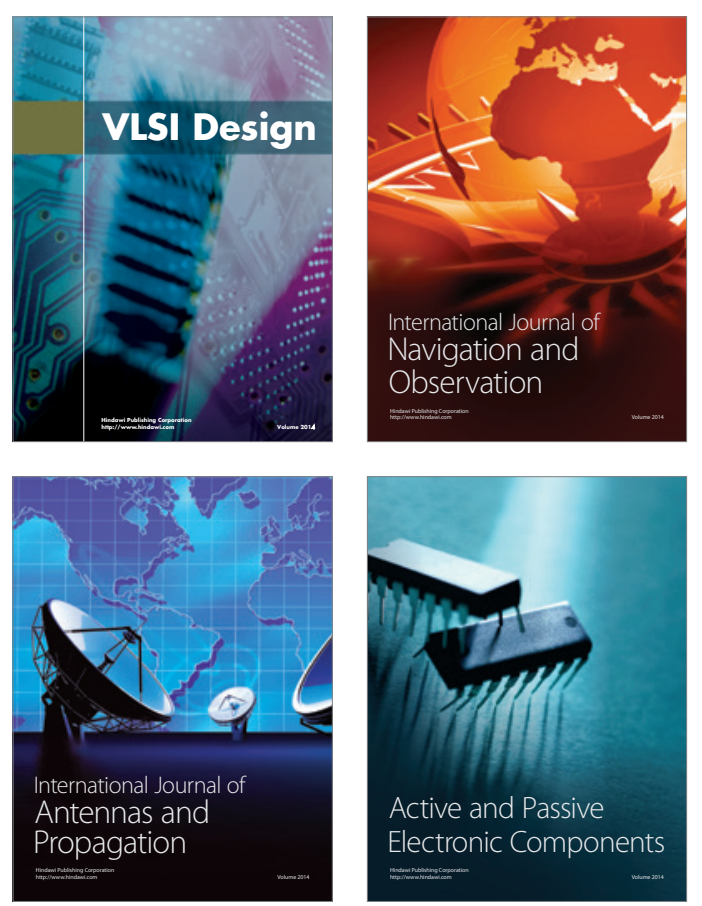
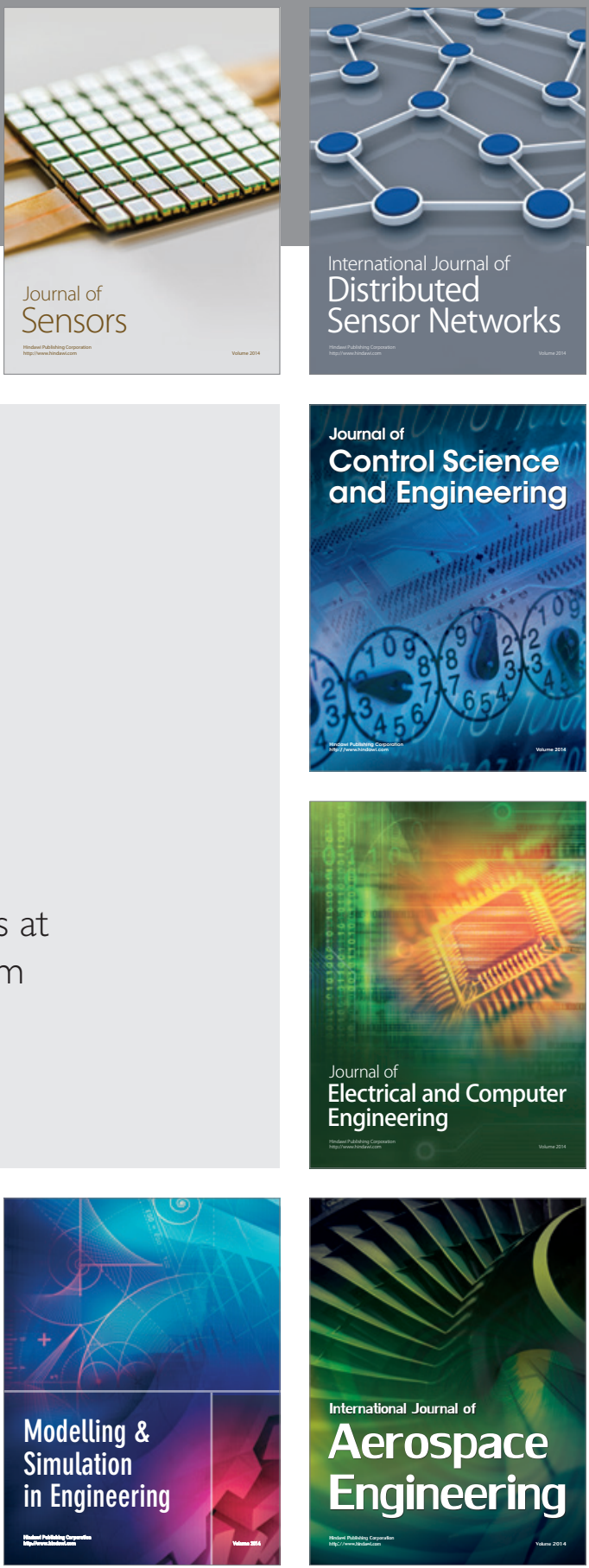

Journal of

Control Science

and Engineering
